\title{
New Proton Conductive Composite Materials for PEM Fuel Cells
}

Serguei Lvov (Primary Contact), Mike Chung, Sridhar Komarneni, Elena Chalkova, Mark Fedkin, Chunmei Wang, Wentian Lin, Hyung Kyu Kim, Yunchul Cho, Kanchan Grover, Young Dong Noh, and Joo Young Kim.

The Pennsylvania State University

207 Hosler Building, University Park, PA 16802-5000

Phone: (814) 863-8377; Fax: 814-865-3248

E-mail: lvov@psu.edu

DOE Technology Development Manager: Jason Marcinkoski

Phone: (202) 586-7466

E-mail: jason.marcinkoski@ee.doe.gov

DOE Project Officer: Gregory Kleen

Phone: (303) 275-4875; Fax: (303) 275-4788

E-mail: gregory.kleen@go.doe.gov

Contract Number: DE-FG36-06GO16036

Subcontractors: none

Project Start Date: May 1, 2006

Project End Date: April 30, 2010

Keywords: proton exchange membranes; proton conductive polymers, inorganic and composite materials; elevated temperature and reduced relative humidity, proton exchange membrane fuel cells

\section{Executive Summary}

This project covered one of the main challenges in present-day PEM fuel cell technology: to design a membrane capable of maintaining high conductivity and mechanical integrity when temperature is elevated and water vapor pressure is severely reduced. The DOE conductivity milestone of $0.1 \mathrm{~S} \mathrm{~cm}^{-1}$ at $120{ }^{\circ} \mathrm{C}$ and $50 \%$ relative humidity (RH) for designed membranes addressed the target for the project. Our approach presumed to develop a composite membrane with hydrophilic proton-conductive inorganic material and the proton conductive polymeric matrix that is able to "bridge" the conduction paths in the membrane. The unique aspect of our approach was the use of highly functionalized inorganic additives to benefit from their water retention properties and high conductivity as well. A promising result turns out that highly hydrophilic phosphorsilicate gels added in Nafion matrix improved PEM fuel cell performance by over 50\% compared with bare Nafion membrane at $120{ }^{\circ} \mathrm{C}$ and $50 \% \mathrm{RH}$. This achievement realizes that the fuel cell operating pressure can be kept low, which would make the PEM fuel cell much more cost 
efficient and adaptable to practical operating conditions and facilitate its faster commercialization particularly in automotive and stationary applications.

\section{Objectives}

- Synthesize new cross-linkable polymer proton conductors with excellent mechanical strength and thermo and chemical stability.

- Synthesize highly conductive and hydrophilic inorganic materials of different structural types with different functional groups applied as additives in composite membranes.

- Test inorganic proton conductors in Nafion based composite membranes to select the most promising materials for the future composite membranes based on the newly developed polyolefin proton conductors.

- Formulate composite membrane fabrication methods to provide guidance to develop highly conductive composite membranes.

- Develop a new membrane material based on the combination of inorganic and polymeric proton conductors to be used in PEM fuel cell at $120{ }^{\circ} \mathrm{C}$ and $25-50 \% \mathrm{RH}$.

\section{Accomplishments}

- Proceeded with a series of functionalized copolymers to investigate the effect of polymer microstructure (backbone molecular weight, graft density, graft length, sulfonic acid concentration, ion exchange capacity, etc.) on their morphology, water uptake and proton conductivity.

- Synthesized new cross-linkable polyolefin based proton conductors with excellent mechanical strength, which are very stable under free radical conditions.

- Tested the proton conductivity of newly developed polymer membranes with promising results close to values of Nafion.

- Developed a two-electrode through-plane inorganic conductivity measurement method.

- Synthesized highly conductive inorganic materials of different structural types with different functional groups such as SBA-15, MCM-41, S-ZrO $2, \mathrm{HOM}-1$, and P-Si gels for use in composite membrane preparation.

- Characterized inorganic materials by powder X-ray diffraction, SEM, BET surface area, porosity, IEC, and conductivity.

- Achieved a conductivity of $10 \mathrm{mS} \mathrm{cm}^{-1}$ for $\mathrm{S}-\mathrm{ZrO}_{2}$ at $120{ }^{\circ} \mathrm{C}$ and $100 \% \mathrm{RH}$ and $100 \mathrm{mS} \mathrm{cm}^{-1}$ for phosphosilicate gel with $\mathrm{P} / \mathrm{Si}$ ratio of 1.5 at $120{ }^{\circ} \mathrm{C}$ and $70 \% \mathrm{RH}$.

- Designed a new membrane fabrication route to polymerize inorganic particles in Nafion matrix by using a sol-gel technique.

- $\quad$ Studied thermal stability, swelling, IEC, morphology, physical chemistry properties of composite membranes.

- Tested conductivity of functional inorganic materials in Nafion based composite membranes from aspects of type of inorganic, inorganic loading, and fabrication techniques. 
- Improved the PEM fuel cell performance of newly synthesized membrane by over 50 \% compared with Nafion membrane at high temperature and low RH.

\section{Technical Barriers}

This project addresses the following technical barriers from the Fuel Cells section (3.4.4) of the Hydrogen, Fuel Cells and Infrastructure Technologies Program Multi-Year Research, Development and Demonstration Plan:

- Cost of fuel cell power systems

- Durability of fuel cell systems

- Size and weight of the systems

- Integrity of thermal, mechanical, and chemical stability of composite membranes

- Operation at low relative humidity $\left(\mathrm{P}_{\mathrm{H} 2 \mathrm{O}}=1.5 \mathrm{kPa}\right.$ at inlet or $<10 \%$ relative humidity at $80^{\circ} \mathrm{C}$ ) and start-up from sub-freezing temperatures

- Air, thermal and water management for fuel cell systems

\section{Technical Targets}

In this project fundamental studies on polymer, inorganic, and composite proton conductive membranes were carried out. Insights gained from this project can be applied toward the design and synthesis of composite membranes that meet the following DOE targets for membranes (automotive):

- Membrane conductivity of $0.1 \mathrm{~S} \mathrm{~cm}^{-1}$ at $120^{\circ} \mathrm{C}$ and $1.5 \mathrm{kPa}$ water pressure

- Durability 5000 hours

- Cost: $\$ 5 / \mathrm{kWh}$

\section{Activity Summary}

This project executed with an original hypothesis that to synthesized chain-end and side chain functionalized Teflon-based polymer, serving as an effective interfacial agent, to bind and to assemble the inorganic particles into a continuous medium. These inorganic surfaces are highly hydrophilic and, once hydrated, can preserve the very thin surface layer of adsorbed water (within electrical double layer) up to temperatures above $200{ }^{\circ} \mathrm{C}$ and extremely low relative humidity. At preliminary stage of the development, a series of graft copolymers, containing a hydrophobic backbone and several hydrophilic side chains, were systematically synthesized and examined with the focus of understanding how the polymer microstructure (backbone molecular weight, graft density, graft length, sulfonic acid concentration, ion exchange capacity, etc.) affects their morphology, water uptake and proton conductivity under various environmental conditions (temperature and relative humidity). Polymers involved the backbone of poly(vinylidene fluoride) (PVDF) and the side chains of sulfonated polystyrene (SPS). Synergistically, layered zirconium phosphate, amorphous zirconium phosphate, and amorphous alumina were synthesized and incorporated with PVDF copolymers to study the conductivity and physical integrity 
of composite membranes. After extensive study of adjusting the polymer microstructure, we found that this PVDF based copolymers could not chemically and physically stand the free radical conditions in PEM fuel cell.

In the second stage of the project, Dr.Chung's group endeavored to develop polyethylene (PE) based copolymers. These graft copolymer self-assembled into a microphaseseparated morphology with randomly oriented long range lamella/cylinder ionic channels (with or without inorganic proton conductors) that were imbedded in the hydrophobic semicrystalline PE matrix. This graft copolymer morphology offered a high ion exchange capacity and resistance to excessive water swelling. In order to understand the function of inorganic additives on the membrane conductivity and select promising inorganic materials, two other groups elaborated to develop Nafion/inorganic composite membranes fabricated with different techniques. The detailed results and analysis are discussed below:

Functional and Crosslinkable P(VDF-CTFE) copolymers

For studying the composite PEMs, we have developed a new class of functional and crosslinkable P(VDF-CTFE) copolymers (disclosed in US patent 7,220,807 that was submitted before starting the project and published in Macromolecules, 2007, 40, 5235). These functional copolymers provide good interfacial adhesions between inorganic particles (bridging nanoparticles into a continuous channel) and inorganic/polymer matrix. Synthesis of crosslinkablale P(VDF-CTFE) copolymers with controllable structure, molecular weight and terminal and side chain silane groups was accomplished. By varying the CTFE content, the copolymer crystallinity and flexibility can be controlled. A membrane fabrication procedure (casting from solution followed by thermal compression) was successfully developed. This was a significant step preceding the preparation of the composite PEMs with required properties.

\section{Sulfonated Styrene Grafted Fluoropolymers P(VDF-CTFE)-g-SPS}

Two phase (hydrophobic-hydrophilic) PEM morphology was systematically investigated for understanding the structure-property relationship between polymer morphology and PEM performance. A series of poly(vinylidene fluoride)- $g$-sulfonated polystyrene (PVDF-g-SPS) graft copolymers with relatively well-defined structures were synthesized and studied by varying backbone molecular weight, graft density, graft length, sulfonic acid concentration, ion exchange capacity, etc. Results of the studies are described in Macromolecules, 2008, 41, 9130.

The microstructure of the graft copolymer directly affects PEM morphology, water uptake, and proton conductivity under various conditions (i.e. temperature and humidity). The PVDF-g-SPS graft copolymer with low graft density (0.3-0.8 mol\%) and long SPS graft length forms a well microphase-separated hydrophilic-hydrophobic morphology with long range isotropic ionic channels (lamella/cylinder) imbedded in the high crystalline PVDF matrix. This morphology lowers the critical ion exchange capacity (IEC) and increases water uptake and $\lambda$ value (molar ratio of water to sulfonic acid). The PVDF backbone molecular weight in the hydrophobic matrix controls the width of hydrophilic conduction channels. A high molecular weight PVDF results in a smaller 
channel width, lower water uptake, and resistance to excessive water swelling at a high IEC value. Although the morphology with long range hydrophilic channels is favorable for proton conductivity with low activation energy, it also leads to high sensitivity to humidity, requiring a high RH to achieve high conductivity. In contrast, the moderately high graft density (1.4-2.4 mol\%) PVDF-g-SPS graft copolymers show dispersed clusternetwork morphology with a small cluster diameter — similar to that of Nafion-which is less sensitive to humidity and exhibits smaller water uptake and $\lambda$ value. The proton conductivity is still proportional to humidity warranted by the smaller slope, and the higher activation energy results in a linear increase of proton conductivity with temperature, under the same RH condition. The PVDF-g-SPS graft copolymer with a high graft density (>2.5 mol\%)—-losing most of its crystallinity—exhibits instability (softness) at a high temperature and also exhibits excessive water swelling with a high IEC value.

The PVDF-g-SPS graft copolymer with a combination of a high PVDF backbone molecular weight ( $\mathrm{Mn}>300,000 \mathrm{~g} \mathrm{~mole}^{-1}$ ), very low SPS graft density ( $0.3 \mathrm{~mol} \%$ ), and high graft length (SPS content $>30 \mathrm{~mol} \%$ ) presents an interesting material for the proton exchange membrane. This graft copolymer self-assembles into a microphase-separated morphology with randomly oriented long range lamella/cylinder ionic channels (with small widths) that are imbedded in the hydrophobic semicrystalline PVDF matrix. This graft copolymer morphology offers a high ion exchange capacity (IEC $=2.75 \mathrm{mmol} \mathrm{g}^{-1}$ ) and exhibits high proton conductivity, exceeding Nafion at $120{ }^{\circ} \mathrm{C}$ and $50 \%$ and $70 \%$ of $\mathrm{RH}$ at high sulfonation degrees. Relatively high swelling and insufficient mechanical and chemical integrity of the tested membranes still calls for further improvement.

We explored different avenues to improve the mechanical properties and to reduce swelling of the P(VDF-CTFE)-g-PS membrane. First, the proton conductivity, swelling, and membrane flexibility were balanced by varying the content of CTFE, amorphous styrene, and the degree of sulfonation. Then, the introduction of hexafluoropropylene (HFP) and increase of molecular weight of the VDF-CTFE copolymer were explored as possible control factors. As a result, the mechanical properties of the membrane were significantly improved, with the conductivity kept above Nafion's conductivity in copolymers of high ion-exchange capacities (IEC) (Figure 1). 


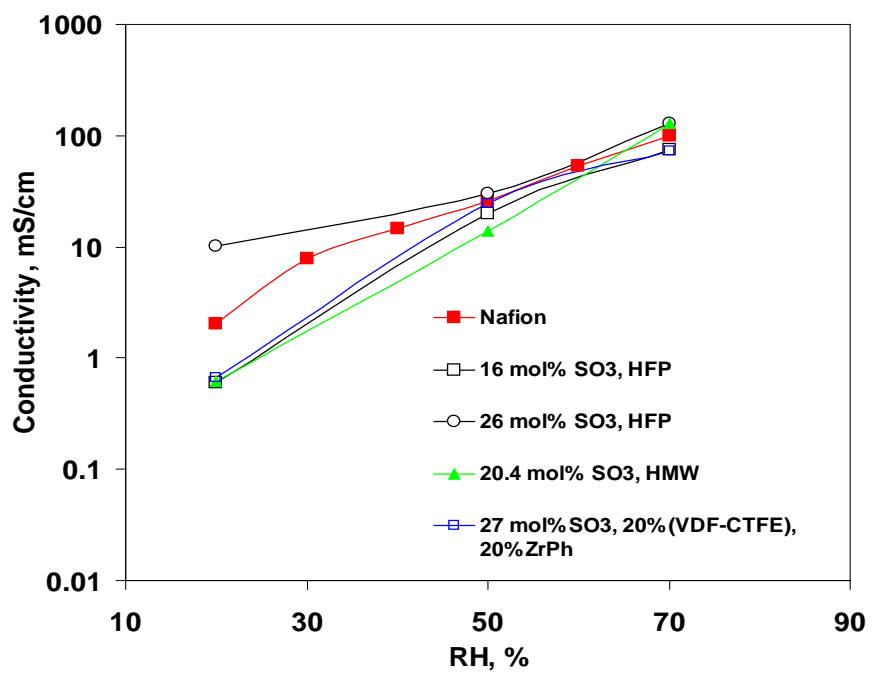

Figure 1. Conductivity of P(VDF-CTFE )-g-PS membranes with additions of HFP, highmolecular-weight VDF-CTFE, and inorganic filler, zirconium phosphate $(\mathrm{ZrPh})$ $\mathrm{H}_{3} \mathrm{OZr}_{2}\left(\mathrm{PO}_{4}\right)_{3}$, measured at $120{ }^{\circ} \mathrm{C}$ as a function of $\mathrm{RH}$.

\section{Synthesis of PE-co-p-MS-Br Copolymers}

To develop more stable PEM membranes, polyolefin based proton conductive polymer was synthesized and fabricated. As a fuel cell membrane, polyolefin is expected to serve as a separator and a matrix to prevent hydrophilic part from swelling and losing its mechanical strength. By metallocene-mediated polymerization, polyethylene (PE) copolymers (PE-co-p-MS) containing para-methylstyrene (p-MS) units was synthesized, followed by bromination at benzylic position of p-MS units by free radical reaction to form brominated PE-Co-p-MS copolymers (PE-co-p-MS-Br). Experimental results show effective reaction to anchor bromine at the benzylic position.

\section{Synthesis PE-g-BAPS}

Bisphenol A polysulfone (BAPS) was synthesized by nucleophilic aromatic substitution polycondensation, as described by many published papers. The graft copolymer of PE-gBAPS was synthesized by graft-onto reaction between PE-co-p-MS-Br and BAPS, as illustrated in Figure 2. There is a potential for crosslinking reaction during coupling process, because two $\mathrm{OH}$ end groups in BAPS polymer that can react with two $\mathrm{Br}$ units in two different PE chains. Thus, in order to prevent crosslinking, mole of $\mathrm{OH}$ in BAPS was designed to be larger than that of $\mathrm{Br}$ units in PE-co-p-MS-Br at all times. 


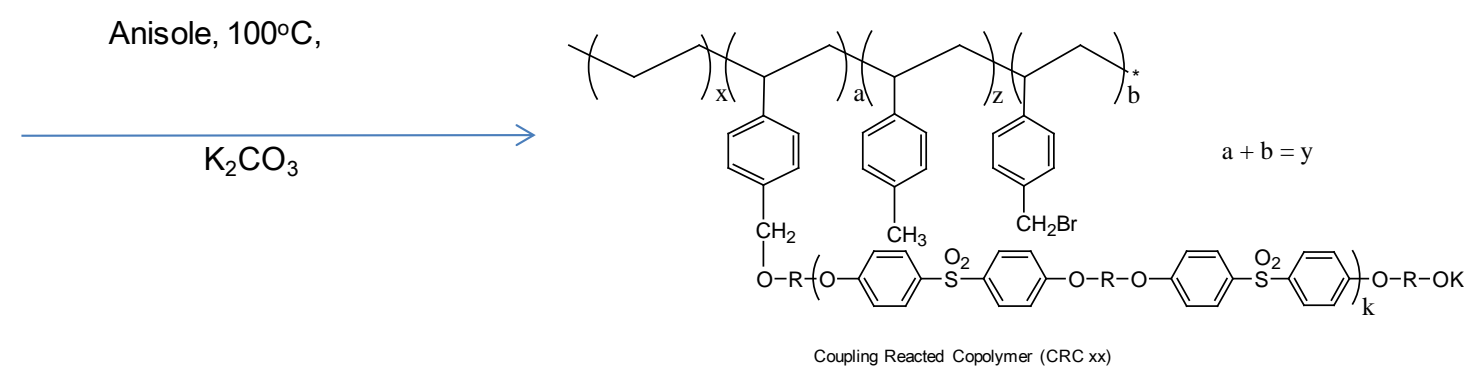

Figure 2. Schematic of graft coupling reaction between PE-co-p-MS-Br and BAPS.

Here there is a brief description of our approach. To $500 \mathrm{ml}$ round bottom glass reactor, BAPS and potassium carbonate were added with $250 \mathrm{ml}$ anhydrous anisole at $100{ }^{\circ} \mathrm{C}$. To $250 \mathrm{ml}$ round bottom glass reactor, $\mathrm{PE}-\mathrm{co}-\mathrm{p}-\mathrm{MS}-\mathrm{Br}$ was dissolved in $100 \mathrm{ml}$ anhydrous anisole at $100{ }^{\circ} \mathrm{C}$. With the aid of cannula, PE-co-p-MS-Br/anisole solution was transferred into BAPS solution and kept for various reaction times for graft coupling reaction. Out of coupling reaction, polymer solution was precipitated into methyl ethyl ketone (MEK) and completely washed with tetrahydrofuran (THF) for the removal of unreacted BAPS polymer. Purified polymer was dissolved into anhydrous anisole for solution-casting. Table 1 summarizes the experimental conditions and results in the preparation of various PE-g-BAPS graft copolymers.

It was found that the longer reaction time, the higher graft efficiency. Interestingly, high molecular weight of bisphenol A polysulfone did not diminish graft efficiency and density but rather increased both. Moreover, high amount of $\mathrm{Br}$ facilitated graft coupling reaction due to its statistically high probability to react with $\mathrm{OH}$ terminal group in BAPS.

Table 1. Reaction conditions and results of graft-coupling reaction

\begin{tabular}{|c||c||c|c||c||c|c|c|c|c||c||c|}
\hline Run & $\begin{array}{c}\text { Br } \\
(\mathrm{mmol})\end{array}$ & $\begin{array}{c}\text { Br unit in } \\
\mathrm{PE}(\mathrm{mol} \%)\end{array}$ & $\begin{array}{c}\mathrm{OH} \\
(\mathrm{mmol})\end{array}$ & $\begin{array}{c}\text { Time } \\
(\mathrm{h})\end{array}$ & $\begin{array}{c}\text { Ethylene/ } \\
\text { Sulfone } \\
(\text { mole ratio })\end{array}$ & $\begin{array}{c}\text { Graft } \\
\text { density }\end{array}$ & $\begin{array}{c}\text { Graft } \\
\text { Length }\end{array}$ & $\begin{array}{c}\text { PE:PS } \\
\text { (in Wt })\end{array}$ & $\begin{array}{c}\text { Graft } \\
\text { efficiency } \\
(\%)\end{array}$ & $\begin{array}{c}\mathrm{M}_{\mathrm{v}} \text { of } \\
\mathrm{PE}\end{array}$ & $\begin{array}{c}\mathrm{M}_{\mathrm{n}} \text { of } \\
\text { PS }\end{array}$ \\
\hline A-1 & 1 & 2 & 2 & 24 & $93.64 / 6.36$ & 0.28 & 23 & $1: 1$ & 14 & 40000 & 10000 \\
\hline A-2 & 1 & 2 & 2 & 12 & $94.67 / 5.33$ & 0.41 & 13.69 & $1: 0.9$ & 18 & 99000 & 6300 \\
\hline A-3 & 1 & 1.14 & 2 & 12 & $98.3 / 1.7$ & 0.13 & 13.69 & $1: 0.3$ & 15 & 73000 & 6300 \\
\hline A-4 & 1 & 2 & 2 & 24 & $94.94 / 5.06$ & 0.22 & 23 & $1: 0.8$ & 19 & 150000 & 10000 \\
\hline A-5 & 1 & 2 & 2 & 12 & $93.64 / 6.36$ & 0.27 & 23.83 & $1: 1$ & 13 & 150000 & 10000 \\
\hline
\end{tabular}




\begin{tabular}{|c|c|c|c|c|c|c|c|c|c|c|c|}
\hline A-6 & 1 & 2 & 2 & 12 & $84.78 / 15.22$ & 0.35 & 43.06 & $1: 2.4$ & 17 & 150000 & 20000 \\
\hline A-7 & 1 & 2 & 2 & 24 & $71.14 / 28.86$ & 0.67 & 43.06 & $1: 4.6$ & 33 & 150000 & 20000 \\
\hline
\end{tabular}

$\mathrm{a}$ - number of PS per 100 ethylene unit, $\mathrm{b}$ - number of sulfone unit in each graft

Sulfonation of PE-g-BAPS Graft copolymers

The PE-g-BAPS graft copolymer was firstly solution-casted on a Teflon plate. After evaporating the solvent, the formed polymer film was hot-pressed to remove defects created during the solvent removal, which may also create some crosslinking structures. The resulting uniform PE-g-BAPS membranes were sulfonated using $0.5 \mathrm{M}$ trimethylsilyl chlorosulfonate (TMSCS) in 1,1,2,2-tetrachloroethane. Sulfonation was done twice or three times in order to achieve high IEC. It turned out that sulfonation of polymer membranes was sufficiently reactive even though sulfonation would be expected to take place on the surface of the membranes. As shown in Table 2, degree of sulfonation reached $100 \%$, with increasing IEC and water uptake at the same time. Runs B-1 and B-2 use low molecular weight A-1 PE-g-BAPS sample, and Runs B-3, B-4, and B-5 involved high molecular weight A-4 PE-g-BAPS sample.

Water uptake (\%) was greatly dependent on the molecular weight of polymer backbone and sulfonation times. Since swelling of hydrophilic side chains would be suppressed by surrounding hydrophobic matrix, high molecular weight of PE backbone would be benefited. In other words, it would be much more resistant to swelling by water than Nafion, thus promising better mechanical strength. As a matter of fact, high molecular weight of functionalized backbone PE significantly diminished water swelling, providing one of desirable properties for PEMs.

IEC value was highly dependent on sulfonation times. Due to film thickness, complete sulfonation of the film would need several sulfonations in order to allow all the activated aromatic rings at side chains to be sulfonated. Proton conductivity was proportional to IEC value and sulfonation times as shown in Table 2. It was interesting to note that proton conductivity of sulfonated coupling reaction copolymer film is the same order with that of Nafion.

Molecular weight of BAPS was another factor which should be controlled to have various IEC values. According to experimental results, high molecular weight of BAPS led to relatively large portion of BAPS in PE-g-BAPS graft copolymer, which allows the polymer to have more sulfonic groups after film sulfonation. Apparently, it was observed that high amount of BAPS in the graft copolymer has high water swelling and IEC (not shown in Table 2). Increasing molecular weight of BAPS and grafting efficiency of coupling reaction are underway.

Table 2. Sulfonation of PE-g-BAPS films and the resulting PE-g-SBAPS properties

\begin{tabular}{|c|c|c|c|c|c|c|}
\hline Run & $\begin{array}{c}\text { Sulfonation } \\
\text { times }\end{array}$ & $\begin{array}{c}\text { IEC } \\
(\mathrm{mmol} / \mathrm{g})^{\mathrm{a}}\end{array}$ & $\begin{array}{c}\text { IEC } \\
(\mathrm{mmol} / \mathrm{g})^{\mathrm{b}}\end{array}$ & $\begin{array}{c}\text { DS } \\
(\%)^{\mathrm{c}}\end{array}$ & $\begin{array}{c}\text { Water } \\
\text { Uptake }(\%)\end{array}$ & $\begin{array}{c}\text { Proton } \\
\text { conductivity } \\
(\mathrm{S} / \mathrm{cm})^{\mathrm{d}}\end{array}$ \\
\hline
\end{tabular}




\begin{tabular}{|c|c|c|c|c|c|c|}
\hline B-1 & 1 & 2.3 & 1.2 & 52 & 100 & 18 \\
\hline B-2 & 2 & 2.3 & 2.1 & 91 & 120 & 48 \\
\hline B-3 & 1 & 2.0 & 0.5 & 25 & 40 & -- \\
\hline B-4 & 2 & 2.0 & 1.5 & 75 & 50 & -- \\
\hline B-5 & 3 & 2.0 & 2.0 & 100 & 67 & -- \\
\hline
\end{tabular}

atheoretical values of IEC assuming that two sulfonic acids per repeat polymer unit, bexperimental value, determined by titration with $0.05 \mathrm{M} \mathrm{NaOH}(\mathrm{aq})$, cpercent of the experimental IEC with respect to the theoretical IEC, d measured at ambient temperature in liquid distillate water.

Synthesis of proton conductive inorganic materials

We synthesized a number of highly conductive and hydrophilic inorganic proton conductive materials with different functional groups. These inorganic materials were characterized by powder X-ray diffraction and scanning electron microscopy (SEM). The BET surface area and porosity of pellets were measured by $\mathrm{N}_{2}$ adsorption/desorption isotherm analysis. The IEC was measured by titration with $\mathrm{NaOH}(\mathrm{aq})$ solution after the completion of ion exchange with $\mathrm{NaCl}(\mathrm{aq})$.

Amorphous zirconium phosphate, layered zirconium phosphate, and three dimensional proton containing zirconium phosphate, $\mathrm{H}_{3} \mathrm{OZr}_{2}\left(\mathrm{PO}_{4}\right)_{3}$, have been prepared to determine the role of structure on conductivity. Preliminary studies showed that $\mathrm{H}_{3} \mathrm{OZr}_{2}\left(\mathrm{PO}_{4}\right)_{3}$ might be a good inorganic proton conductive material when combined with a telechelic PVDF polymeric material synthesized by Dr. Chung's group. We also made mesoporous alumina to check it for conductivity. This mesoporous alumina has a surface area of 450 $\mathrm{m}^{2} / \mathrm{g}$ while the calcined alumina has a surface area of $323 \mathrm{~m}^{2} / \mathrm{g}$. In addition, we synthesized $\mathrm{H}_{3} \mathrm{O}\left(\mathrm{Zr}_{2-\mathrm{x}} \mathrm{Sn}_{\mathrm{x}}\right)\left(\mathrm{PO}_{4}\right)_{3}$ using Sn substitution for $\mathrm{Zr}$, and measured the surface area of this sample and found it to be $23 \mathrm{~m}^{2} / \mathrm{g}$. This surface area is higher than that of $\mathrm{H}_{3} \mathrm{O}\left(\mathrm{Zr}_{2}\right)\left(\mathrm{PO}_{4}\right)_{3}$, which was $8.7 \mathrm{~m}^{2} / \mathrm{g}$, since $\mathrm{H}_{3} \mathrm{O}\left(\mathrm{Zr}_{2-\mathrm{x}} \mathrm{Sn}_{\mathrm{x}}\right)\left(\mathrm{PO}_{4}\right)_{3}$ has a smaller particle size as revealed by SEM. We also made a three dimensional network structure of titanosilicate, $\mathrm{H}_{2}\left(\mathrm{SiTi}_{2} \mathrm{O}_{7}\right) 1.5 \mathrm{H}_{2} \mathrm{O}$ with protons located in the tunnels; this material has a surface area of $70 \mathrm{~m}^{2} / \mathrm{g}$. The particle size was found to be in the range of 0.3 to $1 \mu \mathrm{m}$ by SEM. We synthesized ultrafine zirconia, $\left(\mathrm{Ti}_{0.5} \mathrm{Ce}_{0.5}\right) \mathrm{O}_{2}$ and sulfated titania. The surface areas of the synthesized Ti-Ce oxide, zirconia and titania materials were 57, 139 and 34 $\mathrm{m}^{2} / \mathrm{g}$, respectively. In addition, we have prepared sulfonic functionalized mesoporous silicas such as MCM-41, SBA-15 and cubic cage mesoporous materials and microporous sulfonic functionalized silicas. The synthesis and characterization of the various materials have briefly been reported in our paper to be published shortly in J. Electrochemical Soc., 2010. Some of these materials were incorporated in Nafion to make composites and their conductivities were measured.

The most important proton conducting materials that we prepared are described in detail below along with their characterization. Sulfated zirconia $\left(\mathrm{S}-\mathrm{ZrO}_{2}\right)$ was prepared by using 
zirconium oxychloride hydrate $\left(\mathrm{ZrOCl}_{2} \cdot 8 \mathrm{H}_{2} \mathrm{O}\right)$ as the starting material, and aqueous ammonia $\left(\mathrm{NH}_{4} \mathrm{OH}\right)$ and sulfuric acid $\left(\mathrm{H}_{2} \mathrm{SO}_{4}\right)$ as the precipitating agent and sulfating agent, respectively. Concentrated aqueous ammonia solution ( $28 \%$ ) was gradually dropped into $100 \mathrm{ml}$ of $0.2 \mathrm{M} \mathrm{ZrOCl}_{2} \cdot 8 \mathrm{H}_{2} \mathrm{O}$ solution until the $\mathrm{pH}$ was adjusted to 10 . The precipitated white-colored $\mathrm{ZrO}_{2} \cdot \mathrm{nH}_{2} \mathrm{O}$ sol was washed with distilled water several times in the centrifuge until the absence of chloride ions was confirmed by the silver nitrate $\left(\mathrm{AgNO}_{3}\right)$ test. Then $100 \mathrm{ml}$ of $0.2 \mathrm{M} \mathrm{H}_{2} \mathrm{SO}_{4}(\mathrm{aq})$ was added to the zirconia sol and stirred for 6 hours. The final colloidal solution was filtered and dried in air at $60^{\circ} \mathrm{C}$ followed by calcination at $620^{\circ} \mathrm{C}$ for 3 hours.

Several phosphosilicate gels with the P:Si mole ratios of $0.5,1.0$ and 1.5 were prepared based on the previously described procedures (Matsuda et al., 2002). Tetraethoxysilane (TEOS), $\mathrm{Si}\left(\mathrm{OC}_{2} \mathrm{H}_{5}\right)_{4}$, was first diluted with ethanol $(\mathrm{EtOH})$ and then hydrolyzed with $\mathrm{H}_{2} \mathrm{O}$ containing $\mathrm{HCl}(\mathrm{pH}=0.3)$ while stirring at room temperature for $10 \mathrm{~min}$. A stoichiometric amount of $\mathrm{H}_{3} \mathrm{PO}_{4}$ (85\% aqueous solution) was added to the above hydrolyzed solution followed by stirring at room temperature for 3 hours. The mole ratio of TEOS: EtOH: $\mathrm{H}_{2} \mathrm{O}: \mathrm{H}_{3} \mathrm{PO}_{4}$ was 1: 8: $4: x(x=0.5,1.0$ or 1.5). The obtained sols were kept at $50{ }^{\circ} \mathrm{C}$ in a closed Teflon vessel to form wet phosphosilicate gels. The wet gels were subsequently dried at $50{ }^{\circ} \mathrm{C}$ for an additional week in the Teflon vessel in open air. The dried gels were pulverized into powders with an agate mortar and a pestle followed by heating in an oven at $150^{\circ} \mathrm{C}$ for 5 hours.

To synthesize periodic ordered sulfonic functionalized SBA mesostructures, poly(ethylene oxide)-poly(propylene oxide)-poly-(ethylene oxide) block copolymer species (Pluronic 123) was used as the templating surfactant. The one-step procedure of co-condensation of TEOS and 3-mercaptopropyltrimethoxysilane (MPTMS), with Pluronic 123 species was used as follows: 4g of Pluronic123 was dissolved in $125 \mathrm{ml}$ of $2 \mathrm{M} \mathrm{HCl}$ (aq) at room temperature. The solution was heated to $40{ }^{\circ} \mathrm{C}$ before adding $7.4 \mathrm{~g}$ of TEOS. After 4 hours of stirring, $1.6 \mathrm{~g}$ of MPTMS was added. The resulting mixture was stirred at $40^{\circ} \mathrm{C}$ for 20 hours, and then the mixture was aged hydrothermally at 100 ${ }^{\circ} \mathrm{C}$ for 24 hours. The solid product was recovered by centrifugation and washed with distilled water and dried at $60{ }^{\circ} \mathrm{C}$. The above material was then treated hydrothermally at $90{ }^{\circ} \mathrm{C}$ for 24 hours with $\mathrm{H}_{2} \mathrm{O}_{2}$, ethanol, and $\mathrm{HCl}$. The thiol groups of MPTMS were oxidized with $\mathrm{H}_{2} \mathrm{O}_{2}$ to form sulfonic groups. Ethanol and $\mathrm{HCl}$ (aq, 2M) were used to remove template in a one-step. In this meso-structured material, the siloxane [ $\mathrm{Si}(\mathrm{OSi})_{\mathrm{n}^{-}}$$\left.(\mathrm{OH})_{4-\mathrm{n}}, \mathrm{n}=2-4\right]$ and organosiloxane $\left[\mathrm{HO}_{3} \mathrm{~S}\left(\mathrm{CH}_{2}\right)_{3} \mathrm{Si}(\mathrm{OSi})_{\mathrm{m}}-(\mathrm{OH})_{3-\mathrm{m}}, \mathrm{m}=1-3\right]$ units were present. The sulfonic groups were covalently attached on the pore walls of the silica.

\section{Proton conductivity of inorganic materials}

In order to study the proton conductivity of inorganic materials, a two-electrode throughplan conductivity measurement method was developed. Inorganic pellets were sandwichheld between sample holders. Figure 3 shows the schematic of the sample assembly. 


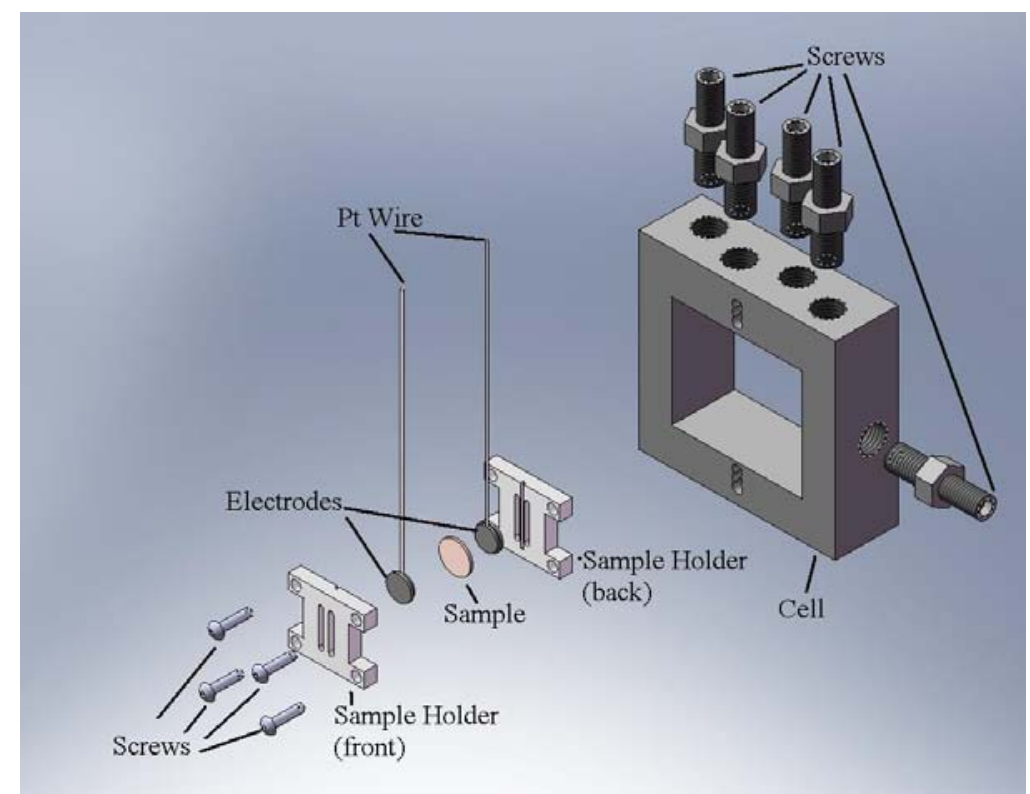

Figure 3. Schematic of through-plane conductivity measurement assembly.

An inorganic sample was prepared by pressing $300 \mathrm{mg}$ of powder into a pellet of $13 \mathrm{~mm}$ in diameter and 1-2 $\mathrm{mm}$ in thickness under the pressure of about $5 \mathrm{t} \mathrm{cm}^{-2}$. The pellet was then annealed at $200{ }^{\circ} \mathrm{C}$ for 6 hours. On each side of the pellet surface Ag was painted to serve as electrodes. The designed Teflon sample holders and two flat Ag plates soldered with two Pt wires were used to sandwich-hold the sample and then assembled in the BekkTech hardware. A Gamry Electrochemical Impedance Spectroscopy (EIS) system with a frequency range of 0.2 to $100 \mathrm{kHz}$ was used to measure the AC conductivity of the inorganic samples. A linear 2-electrode DC sweeping from $-10 \mathrm{mV}$ to $+10 \mathrm{mV}$ was used to check the electron conductivity of the samples. If the sweeping at low potential produced a linear response, the inorganic sample was considered to conduct electrons because the over-potential was insufficient to begin splitting water and to generate hydrogen and oxygen. We found that the designed method can be used for reliable conductivity measurements over wide ranges of temperatures from 25 to $120^{\circ} \mathrm{C}$ and RHs from 1 to $100 \%$ ). The precision of temperature control was $\pm 0.2{ }^{\circ} \mathrm{C}$ and the calculated error to estimate $\mathrm{RH}$ was $\pm 0.5 \%$.

Some of our conductivity measurements are shown in Figures 4, 5, and 6. Figure 4 shows that at elevated temperatures, a fully-hydrated $(\mathrm{RH}=100 \%) \mathrm{S}-\mathrm{ZrO}_{2}$ can provide a high proton conductivity up to $10 \mathrm{mS} \mathrm{cm}^{-1}$. Hara et al. (2004) found that the $\mathrm{SO}_{\mathrm{x}}$ groups exist on the $\mathrm{ZrO}_{2}$ surface; these groups are electron-withdrawing and strengthen the Lewis and Brønsted acidities of $\mathrm{Zr}$; the feature enhances the proton conductivity. In phosphorsilicate gels, crystal structure unit, $\mathrm{Si}_{5} \mathrm{O}\left(\mathrm{PO}_{4}\right)_{6}$, could be readily hydrolyzed at high $\mathrm{RH}$, forming isolated phosphoric acid and $\mathrm{Si}-\mathrm{O}-\mathrm{POH}$ groups. These groups are beneficial for enhancement of the proton conductivity (Matsuda et al., 2001). Phosphorsilicate gels with the P:Si ratio of 1.5 has a better proton conductivity than the gel with the P:Si ratio of 0.5 . At $120{ }^{\circ} \mathrm{C}$ and $70 \% \mathrm{RH}$, the gel with the P:Si ratio of 1.5 reaches a high conductivity value of $0.100 \mathrm{~S} \mathrm{~cm}^{-1}$, which is the same or even higher than that of Nafion. In SBA-15, the siloxane groups $\mathrm{Si}-\mathrm{O}-\mathrm{Si}-\mathrm{OH}$ and sulfonic groups $-\mathrm{SO}_{3} \mathrm{H}$ on the mesopore surfaces 
provide proton diffusion through the sample. At $70 \% \mathrm{RH}$, SBA-15 reached a conductivity value of $0.04 \mathrm{mS} \mathrm{cm}^{-1}$, which was not as high as those of other inorganic conductors. However, its high surface area and the presence of sulfonic acid functional groups seem beneficial to be compatible with polymer membranes.

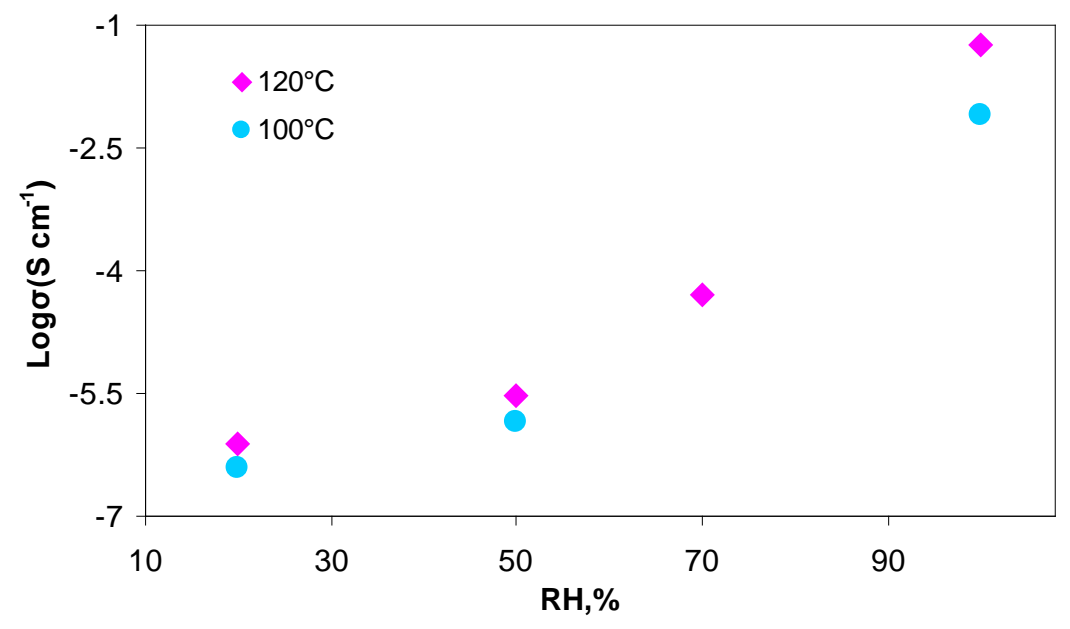

Figure 4. Proton conductivity of $\mathrm{S}-\mathrm{ZrO}_{2}$ at $100{ }^{\circ} \mathrm{C}$ and $120^{\circ} \mathrm{C}$ as a function of $\mathrm{RH}$.

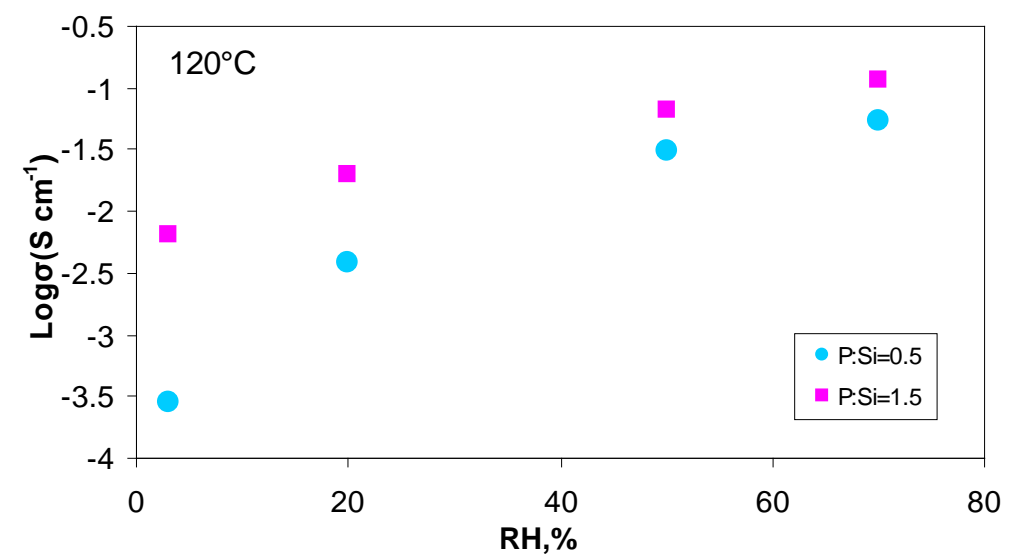

Figure 5. Proton conductivity of $\mathrm{P}-\mathrm{SiO}_{2}$ with different $\mathrm{P}$ : Si ratios at $120^{\circ} \mathrm{C}$ as a function of RH. 


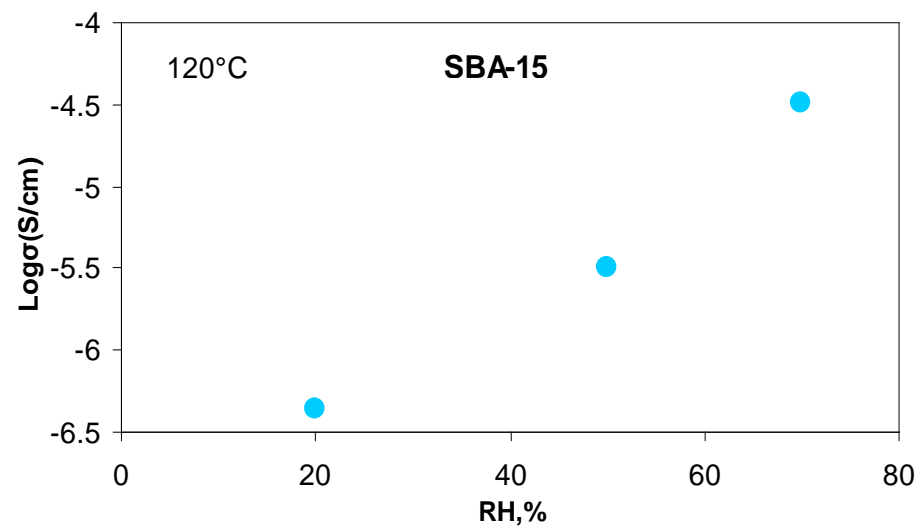

Figure 6. Proton conductivity of SBA-15 at $120{ }^{\circ} \mathrm{C}$ as as a function of $\mathrm{RH}$.

\section{Fabrication of composite membrane}

Initial composite membranes were synthesized by incorporating 3-D phase zirconium phosphate, sulfonated silica and sulfonated trimethoxyl phenyl silane with telechelic VDF/CTFE polymers. Composite membranes were fabricated using solution casting of polymer/inorganic suspension followed by thermal compressing. Membrane conductivity was studied with a four-electrode in-plane method. A linear DC sweeping from $-100 \mathrm{mV}$ to $+100 \mathrm{mV}$ was applied to measure the resistance of composite membranes. (VDF$\mathrm{CTFE} / \mathrm{Nafion} / \mathrm{H}_{3} \mathrm{OZr}_{2}\left(\mathrm{PO}_{4}\right)_{3}$ membranes reached a conductivity at $120{ }^{\circ} \mathrm{C}$ up to 0.025 and $0.008 \mathrm{~S} \mathrm{~cm}^{-1}$, at 70 and $50 \% \mathrm{RH}$, respectively. We tried to tune the crosslink, the content of terminal silane groups $\left[\mathrm{Si}\left(\mathrm{OC}_{2} \mathrm{H}_{5}\right)_{3}\right]$, and the structure network of VDF/CTFE polymers to achieve required proton conductivity. However, it turned out this VDF/CTFE based polymers are not chemically and physically stable to properly survive in the harsh fuel cell environments. We were endeavored to develop new polymer materials for composite membranes.

At the same time, in order to compare the properties and behavior of different inorganic materials under fuel cell conditions, we prepared and characterized Nafion/inorganic composite membranes. Nafion was chosen as the reference matrix material for such series because it is the best studied polymer with well-known properties. Three different techniques were used to fabricate Nafion/inorganic composite membranes by: (1) blending of inorganic powders with Nafion solution followed by casting and annealing, (2) in situ forming the inorganic particles from infiltration of precursor solution into Nafion film, and (3) in situ forming the inorganic particles from precursor in Nafion solution followed by casting and heat treatment. Technique (1) was used for the preparation of composite membranes with all inorganic materials, while techniques (2) and (3) were used for the preparation of Nafion/P-Si gel composite membranes only.

Characterization of composite membrane

The membranes prepared by technique (1) were tested for swelling, IEC, conductivity and fuel cell performance. It was found that the IEC of all Nafion/inorganic composite membranes was higher than that of Nafion. The conductivity of composite membranes with $10 \%$ of different sulfonated inorganic, was different for different membranes but not 
higher than the conductivity of recast Nafion. None of these inorganic materials enhanced the conductivity of polymeric matrix. The conductivity measurements of composite membranes were in agreement with their IEC. No correlation between membrane conductivity and swelling was found. The effect of the inorganic content on the membrane conductivity was evaluated on a series of $\mathrm{Nafion} / \mathrm{SiO}_{2}-\mathrm{SO}_{3} \mathrm{H}$ composite membranes with different $\mathrm{SiO}_{2}-\mathrm{SO}_{3} \mathrm{H}$ content $(10-120 \%)$. The increase in $\mathrm{SiO}_{2}-\mathrm{SO}_{3} \mathrm{H}$ content above $10 \%$ gradually decreased the membrane conductivity, probably, due to particle agglomeration. No conductivity enhancement was found when doping level was decreased to $0.5-3 \%$ (Nafion/3\%S-ZrO ${ }_{2}$, Nafion/0.5\%P-Si, and Nafion/0.5\%SBA-15 membranes). It was found that the conductivity of Nafion/phosphosilicate gel composite membranes was affected by surface area of P-Si gel powder.

The effect of membrane fabrication technique was evaluated on Nafion/10\% phosphosilicate gel membranes. The performance of the membrane prepared by blending of inorganic powders with Nafion (Technique 1) was the lowest. The performance of the membranes prepared by in situ formation of inorganic particles in Nafion (Techniques 2 and 3) was higher and very close to each other (Figure 7). The effect of inorganic phase on membrane performance in fuel cell was much stronger. The resistance of Nafion/10\% P-Si gel composite membrane in a fuel cell was $40-50 \%$ less, and the limiting current about $40-50 \%$ higher than those of pure recast Nafion (Figure 8).

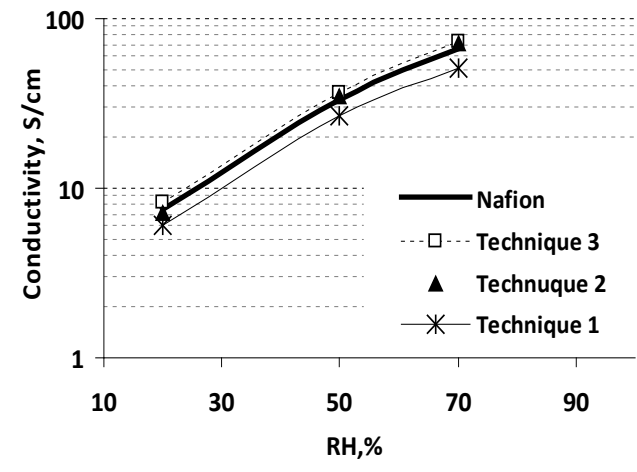

a

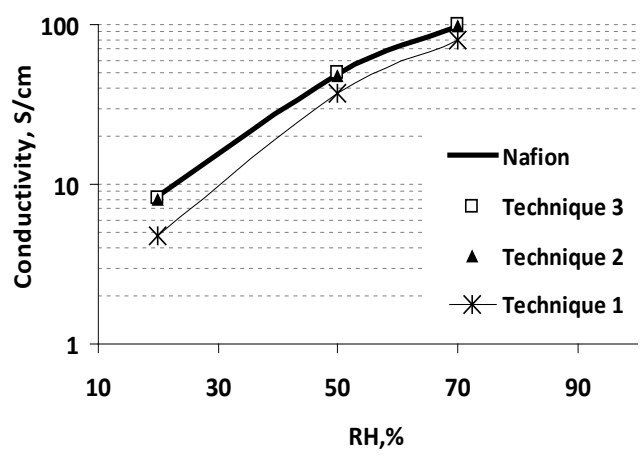

b

Figure 7. Conductivity of Nafion/10\% P-Si gel composite membranes prepared using different techniques at $80{ }^{\circ} \mathrm{C}$ (a) and $120{ }^{\circ} \mathrm{C}$ (b) and different $\mathrm{RH}$. 


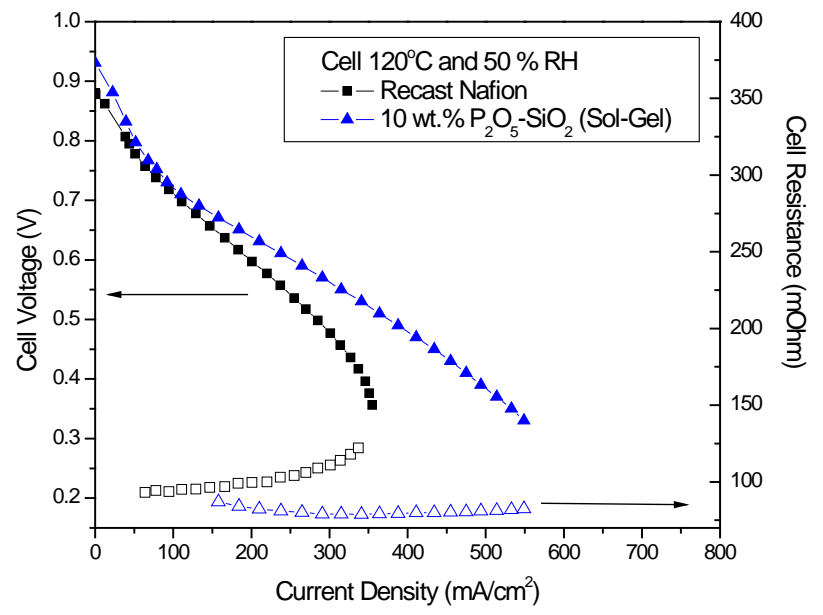

a

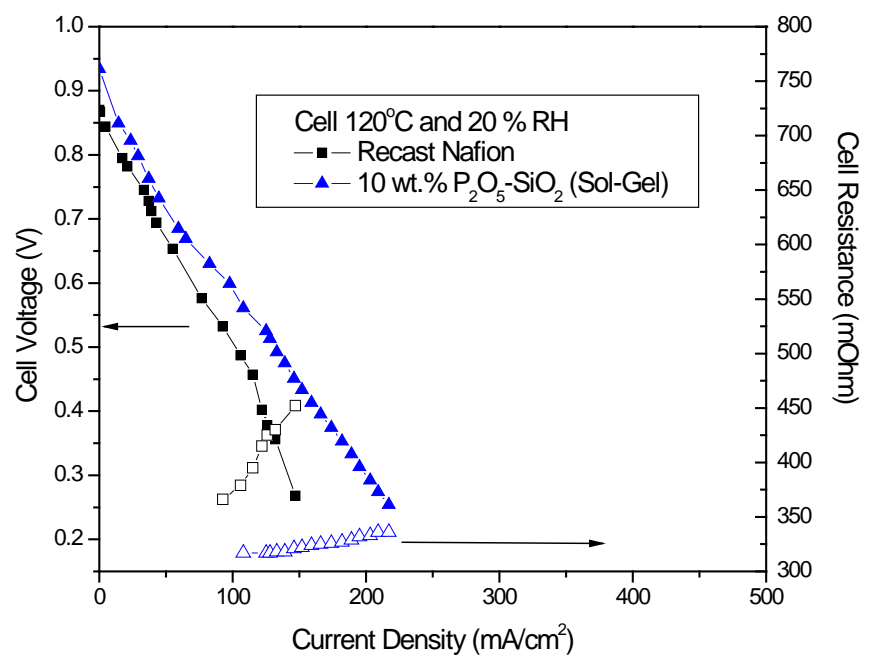

b

Figure 8. Conductivity of Nafion/10\% P-Si gel composite membranes prepared using different techniques at $80{ }^{\circ} \mathrm{C}$ (a) and $120{ }^{\circ} \mathrm{C}$ (b) and different $\mathrm{RH}$.

\section{Conclusions and Future Directions}

The results of the study proved the initial accomplishments of objective-targeted project. The three-year project fulfilled with intense synthesis and characterization of different types of functional inorganic materials, which were investigated in the proton conductivity by newly developed through-plane conductivity technique, and in the contribution to the performance of composite membranes. A variety of inorganic conductors were incorporated in Nafion by different fabrication methods to enhance the basic understanding of interaction between inorganic functional groups with sulfonic 
functional groups in Nafion. This understanding helped us to select the most promising inorganic materials for the future composite membranes based on the newly developed polymeric materials. In the third year, we successfully developed polyolefin based polymeric proton conductors with excellent mechanical strength and promising proton conductivity. These polyolefin based polymers are used to replace the previous studied polymers, VDF-CTFE copolymers. The next step should be the development of composite sulfonated polyolefin/inorganic membranes. The first candidate for testing should be sulfonated PE/phosphosilica gel membrane fabricated using in situ formation technique.

\section{References}

Hara, S. and M. Miyayama, Proton conductivity of superacidic sulfated zirconia. Solid State Ionics, 2004. 168(1-2): p. 111-116

Matsuda, A., et al., Medium temperature range characterization as a proton conductor for phosphosilicate dry gels containing large amounts of phosphorus. Electrochimica Acta, 2001. 47(6): p. 939-944.

Matsuda, A., Kanzaki T., Tadanaga K., Tatsumisago M, and Minami T., Solid State Ionics, 154-155, 687 (2002).

\section{Publications/Presentations}

1. S.N. Lvov, Surface Chemistry of Solid Oxide Materials for High Temperature PEMFCs, The $84^{\text {th }}$ Colloid and Surface Science Symposium, ACS Division of Colloid and Surface Sciences, Akron, OH, USA, June 2010 (keynote presentation).

2. C. Wang, E. Chalkova, C.D. Lute, M.V. Fedkin, S. Komarneni, T.C. M. Chung, and S.N. Lvov, Proton Conductive Inorganic Materials at Temperatures up $120{ }^{\circ} \mathrm{C}$ and Relative Humidity Down to 5 \%. J. Electrochemical Soc., 2010, 157, B1634-B1642.

3. Z. Zhang, E. Chalkova, M. Fedkin, C. Wang, S. N. Lvov, S. Komarneni, and T. C. Mike Chung, Poly(vinylidene fluoride)- $g$-sulfonated polystyrene Graft Copolymers for Proton Exchange Membrane, In "Fuel Cell Chemistry and Operation" Ed. A. Herring, ACS. Symposium Book, 2009.

4. E. Chalkova, C. Wang, S. Komarneni, J. Lee, M. Fedkin, and S. Lvov, Composite Proton Conductive Membranes for Elevated Temperature and Reduced Relative Humidity PEMFC, The $216^{\text {th }}$ Electrochemical Society Meeting, Vienna, Austria, October 2009 (oral presentation).

5. E. Chalkova, C. Wang, S. Komarneni, J. Lee, M. Fedkin, and S. Lvov, Composite Proton Conductive Membranes for Elevated Temperature and Reduced Relative Humidity PEMFC, ECS Tans., 25(1), 1141 - 1150, 2009.

6. C. Wang, E. Chalkova, C. Lute, M. Fedkin, S. Komarneni, M. Chung, and S. Lvov, Proton Conductive Inorganics for Composite Membranes in PEM Fuel Cells, ECS Tans., 16(2), 1451 - 1459, 2008.

7. Fedkin M.V., Chalkova E. , Wesolowski D. J., and Lvov S.N., Understanding the Water Retention of Composite Proton Exchange Membranes Based on Surface Chemistry of Inorganic Fillers, ECS Trans., 11, 189-198, 2008. 
8. Z. Zhang, E. Chalkova, M. Fedkin, C. Wang, S. N. Lvov, S. Komarneni, and M. Chung, Synthesis and characterization of poly(vinylidene fluoride)-g-sulfonated polystyrene graft copolymers for proton exchange membranes, Macromolecules, 41, (23), 9130-9139 (2008).

9. C. Wang, E. Chalkova, C. Lute, M. Fedkin, S. Komarneni, M. Chung, and S. N. Lvov, Proton Conductive Inorganics for Composite Membranes in PEM Fuel Cells, The $214^{\text {th }}$ Electrochemical Society Meeting, Pacific Rim, Hawaii, October 2008 (oral presentation).

10. M. Chung, Z. Zhang, E. Chalkova, C. Wang, M. Fedkin, S. Komarneni, S. N. Lvov, and T. L. Payne, New proton conductive composite materials with inorganic and styrene grafted and sulfonated vdf/ctfe fluoropolymers, The $236^{\text {th }}$ American Chemical Society National Meeting, Philadelphia, PA, August 2008, (oral presentation).

11. Z. Zhang, E. Chalkova, M. Fedkin, C. Wang, S. N. Lvov, S. Komarneni, and T. C. Mike Chung, Recent Advances In Proton Conductive Materials Using Styrene Grafted and Sulfonated VDF/CTFE Fluoropolymers, The 213th Electrochemical Society Meeting, Phoenix, AZ, May, 2008.

12. C. Wang, E. Chalkova, M. Fedkin, S. Komarneni, T. C. M. Chung, and Serguei N. Lvov, Conductivity studies of inorganic proton conductors for composite membranes in PEM fuel cells, $13^{\text {th }}$ ECS Meeting Phoenix, May 18, 2008.

13. M. Chung, Z. Zhang, E. Chalkova, C. Wang, M. Fedkin, S. Komarneni, and S. N. Lvov, Recent advance in proton conductive materials using styrene grafted and sulfonated VDF/CTFE fluoropolymers, $13^{\text {th }}$ ECS Meeting Phoenix, May 18, 2008.

14. Chalkova E., Fedkin M. V., Komarneni S., Lvov S. N., Nafion/Zirconium Phosphate Composite Membranes for PEMFC Operating at up to $120{ }^{\circ} \mathrm{C}$ and Down to $13 \% \mathrm{RH}$. J. Electrochemical Soc., 2007, 154, B288-B295.

15. M. Chung, Z. Zhang, E. Chalkova, C. Wang, M. Fedkin, S. Komarneni, S. Sharma, and S. Lvov, Proton Conductive Composite Materials Using Functionalized and Crosslinkable VDF/CFTE Fluoropolymers and Proton Conductive Inorganics, The $212^{\text {th }}$ Electrochemical Society Meeting, Washington DC, October, 2007.

16. S. Lvov, M. Chung, S. Komarneni, Z. Zhang, E. Chalkova, S. Sharma, M. Fedkin, and C. Wang, New Proton Conductive Composite Materials with Co-continuous Phases Using Functionalized and Crosslinkable VDF/CTFE Fluoropolymers, The 2007 DOE Hydrogen Program Review Meeting, May 15-18, 2007, Arlington, VA (oral presentation).

17. M. Chung, Z. Zhang, E. Chalkova, C. Wang, M. Fedkin, S. Komarneni, S. Sharma, and S. Lvov, Proton Conductive Composite Materials Using Functionalized and Crosslinkable VDF/CFTE Fluoropolymers and Proton Conductive Inorganics, ECS Trans., 11(1), 35-47, 2007.

18. M. Chung, S. Komarneni, E. Chalkova, and S.N. Lvov, Proton Conductive Composite Materials with Co-continuous Phases Using Silane Functionalized and Crosslinkable PVDF Polymers, ECS Trans., 3(1), 83-90, 2006.

19. Fedkin, M.V.; Chalkova, E.; Komarneni, S.; Wesolowski, D.J.; Lvov, S.N., Surface Electrochemistry of Composite Materials for High-Temperature PEM Fuel Cells, ECS Trans., 2006, 1, 215-225. 
20. T.C. Mike Chung, S. Komarneni, E. Chalkova, S.N. Lvov, Proton Conductive Composite Materials with Co-continuous Phases Using Silane Functionalized and Crosslinkable PVDF Polymers, The $210^{\text {th }}$ Electrochemical Society Meeting, Cancun, Mexico, October, 2006 (oral presentation).

21. S.N. Lvov, M.V. Fedkin, E. Chalkova, S. Komarneni, and D.J. Wesolowski, Surface Chemistry of Inorganic Materials for Composite Membranes in PEM Fuel Cells Operating at Elevated Temperature and Reduced Relative Humidity, American Chemical Society 232nd National Meeting \& Exposition, September 10-14th, 2006, San-Francisco, CA (oral presentation).

22. S.N. Lvov, M. Chung,S. Komarneni, E. Chalkova, M. V. Fedkin, Z. Zhang, and S. Sharma, New Proton Conductive Composite Materials with Co-continuous Phases Using Functionalized and Crosslinkable TFE/VDF Fluoropolymers, The 2006 DOE Hydrogen Program Review Meeting, May 16-19, 2006, Arlington, VA (poster).

\section{Acronyms}

BAPS - Bisphenol A polysulfone;

BET- Brunauer Emmett Teller;

CTFE - chlorotrifluoroethylene;

DOE - department of energy;

EIS - electrochemical impedance spectroscopy;

EtOH - ethanol;

HFP - hexafluoropropylene;

HOM-1 - sulfonic acid functionalized cubic cage mesoporous silica;

IEC - ion exchange capacity;

MCM-41 - mesoporous silica with arrays of hexagonal channels;

MEK - methyl ethyl ketone;

MPTMS - 3-mercaptopropyltrimethoxysilane;

$\mathrm{PE}$ - polyethylene;

PE-co-p-MS - polyethylene copolymers;

PE-co-p-MS-Br - brominated PE-co-p-MS copolymers;

PEM-polymer electrolyte membrane;

Pluronic 123 - poly(ethylene oxide)-poly(propylene oxide)-poly-(ethylene oxide) block copolymer species;

p-MS - para-methylstyrene;

P-Si gel - phosphorsilicate gel;

PVDF - poly(vinylidene fluoride);

$\mathrm{RH}$ - relative humidity;

SBA-15 - Santa Barbara Amorphous type material, hexagonal mesoporous silica;

SBAPS - sulfonated bisphenol A polysulfone;

SEM-scanning electron microscopy;

SPS - sulfonated polystyrene;

$\mathrm{S}-\mathrm{ZrO}_{2}$ - sulfated zirconia;

TEM- transmission electron microscopy; 
TEOS - tetraethoxysilane;

TMPS - trimethoxyl phenyl silane;

TMSCS - trimethylsilyl chlorosulfonate;

THF - tetrahydrofuran;

$\mathrm{ZrPh}$ - zirconium phosphate 